Phenobarbital protects cerebral cortex neurones against toxicity induced by kainate but not by other excitatory amino acids.

Quistorff, Bjørn; Frandsen, Aase; Schousboe, Arne

Published in:

Neuroscience Letters

Publication date:

1990

Document version

Publisher's PDF, also known as Version of record

Citation for published version (APA):

Quistorff, B., Frandsen, A., \& Schousboe, A. (1990). Phenobarbital protects cerebral cortex neurones against toxicity induced by kainate but not by other excitatory amino acids. Neuroscience Letters, 111((1-2)), 233-238. 


\title{
Phenobarbital protects cerebral cortex neurones against toxicity induced by kainate but not by other excitatory amino acids
}

\author{
Aase Frandsen 1,", Bjørn Quistorff ${ }^{2}$ and Arne Schousboe ${ }^{1, *}$ \\ 'PharmaBiotec Research Center, The Neurobiology Unit, Department of Biochemistry A, Panum Institute, \\ University of Copenhagen, Copenhagen (Denmark) and ${ }^{2} N M R$ Center, Department of Biochemistry A, \\ Panum Institute, University of Copenhagen, Copenhagen (Denmark)
}

(Received 4 September 1989; Revised version received 15 November 1989; Accepted 20 November 1989)

Key words: Cortical neuron; Toxicity; Oxygen uptake; Excitatory amino acid; Barbiturate; Phenobarbital; Kainate

The effect of phenobarbital (PB) on the cytotoxicity induced by the excitatory amino acids (EAAs) glutamate, aspartate, $N$-methyl-D-aspartate (NMDA), kainate (KA), quisqualate (QA) and $R S$ - $\alpha$-amino-3hydroxy-5-methyl-4-isoxazolopropionate (AMPA) was investigated in cultured cerebral cortex neurones. PB $(100 \mu \mathrm{M})$ completely protected against the total cytotoxic damage induced by KA, whereas it had no such effect on the toxicity induced by any of the other EAAs. The $\mathrm{IC}_{50}$ for the inhibition of the KA induced toxicity was $56 \mu \mathrm{M}$. Furthermore, $\mathrm{PB}$ completely blunted the large increase in $\mathrm{O}_{2}$ uptake in the neurones seen during exposure of the cultures to KA. Since exposure of the cells to PB alone did not affect the basal $\mathrm{O}_{2}$ consumption in the cultures, these results suggest that $\mathrm{PB}$ directly interacts with the KA receptor or, alternatively, with processes which selectively are coupled to activation of the KA receptor but not to activation of other types of EAA receptors.

The neurotoxic action of the excitatory amino acids (EAAs) kainate (KA), $N$-methyl-D-asparatate (NMDA), quisqualate (QA) and $R S$ - $\alpha$-amino-3-hydroxy-5methyl-4-isoxazolopropionate (AMPA) is thoroughly described $[2,6,7,8,17]$. In addition to the toxic actions, EAAs are thought to be involved in convulsive disorders [1]. Barbiturates such as phenobarbital (PB) are widely used as anticonvulsants and this group of compounds also comprise drugs which act as anaesthetics. These latter ones are GABA-mimetics in low concentrations whereas the anticonvulsant barbiturates are not [15]. However, both types of barbiturates depress glutamate mediated transmission $[15,21]$. In agreement with this, pretreatment of experimental animals

\footnotetext{
*Present address: PharmaBiotec Research Center, The Neurobiology Unit, Department of Biology, Royal Danish School of Pharmacy, DK-2100 Copenhagen, Denmark.

Correspondence: Aa. Frandsen, PharmaBiotec Research Center, The Neurobiology Unit, Department of Biology, Royal Danish School of Pharmacy, 2 Universitetsparken, DK-2100 Copenhagen, Denmark.
} 
with phenobarbital has been shown to abolish KA induced seizures but the exact mechanism is unknown [9]. Although part of this effect may be the result of a reduced release of glutamate [21] the barbiturate depression of glutamate transmission might also reflect an interaction between barbiturates and specific receptors for EAAs [3]. So far conflicting conclusions have been reached on the basis of studies on these mechanisms conducted in more simple systems such as nerve-cell cultures [2, 12]. Thus, Koh and Choi [12] using glutamate as a representative of EAAs concluded that the in vivo protective effect of anticonvulsant drugs on EAA induced toxicity must be indirect. In order to obtain more direct information on a possible interaction between anticonvulsant barbiturates and EAA receptor mediated cytotoxicity, the present study was undertaken to investigate the possible protective effect of phenobarbital on the cytotoxicity induced by different EAAs.

Cultures of cerebral cortex neurones were obtained from 15-day-old mouse fetuses as detailed by Frandsen and Schousboe $[6,7]$. Astrocytic contamination was curtailed by addition after $48 \mathrm{~h}$ of $20 \mu \mathrm{M}$ of the mitotic inhibitor cytosine arabinoside [4]. The neurones were routinely cultured for 9 days before exposure to the different EAAs and toxicity was measured using the lactate dehydrogenase ( $\mathrm{LDH}$-) leakage test as detailed by Frandsen and Schousboe [6, 7]. To prevent underestimation of the toxicity induced by glutamate and aspartate [7] $500 \mu \mathrm{M}$ of the glutamate uptake inhibitor [5] L-aspartate- $\beta$-hydroxamate was included in the incubation media when the cultures were exposed to either one of these EAAs. Neurones used for measurement of $\mathrm{O}_{2}$ consumption were cultured for 6-10 days. Oxygen uptake was measured by using an Clarck-type $\mathrm{O}_{2}$-electrode and the oxygen consumption rate calculated as described by Robinson and Cooper [20].

Cells were washed twice with a Ringer buffer containing $140 \mathrm{mM} \mathrm{NaCl}, 4 \mathrm{mM}$ $\mathrm{KCl}, 1 \mathrm{mM} \mathrm{CaCl}_{2}, 2 \mathrm{mM} \mathrm{MgCl}, 10 \mathrm{mM}$ glucose and $10 \mathrm{mM}$ HEPES, at pH 7.4, $37^{\circ} \mathrm{C}$, and the culture flasks were subsequently filled with $64.0 \mathrm{ml}$ Ringer $\left(37^{\circ} \mathrm{C}\right)$. The cultures were immediately transferred to a water bath, thermostated to $37^{\circ} \mathrm{C}$ and equipped with a magnetic stirrer held under the top wall of the culture flask (opposite to the cell layer) to ensure a representative $\mathrm{O}_{2}$ concentration at the electrode. Air bubbles were carefully removed from the culture flasks before experiments were performed, these precautions being absolutely essential to obtain reproducible results. The $\mathrm{O}_{2}$ electrode and a syringe were fitted into the cap of the culture flask allowing exposure of the cultures to KA and PB without opening the system. This system allowed recordings of a constant oxygen consumption of $3-5 \mu \mathrm{mol} \times \mathrm{mg}^{-1}$ protein $\times \mathrm{h}^{-1}$ for more than $12 \mathrm{~h}$. In all experiments the basal $\mathrm{O}_{2}$-uptake was measured over a period lasting 15-60 min during which time the rate of respiration was constant. Protein contents were determined as described by Frandsen and Schousboe [6].

As shown in Table I, only the cytotoxicity induced by KA $(300 \mu \mathrm{M})$ could be prevented by coadministration of PB $(100-500 \mu \mathrm{M})$ whereas the toxicity elicited by glutamate, aspartate, AMPA, NMDA or QA was unaffected by the presence of phenobarbital in the incubation media. Moreover, $1 \mathrm{mM} \gamma$-aminobutyrate (GABA) did not protect the cultures from the cell damage induced by any of the EAAs. This latter finding is in agreement with the results obtained by Olney et al. [18] and Koh and 
TABLE I

EFFECTS OF PB ON THE EAA-INDUCED TOXICITY IN CEREBRAL CORTEX NEURONES CULTURED FOR 9 DAYS

Effect of PB on EAA induced LDH leakage (cytotoxicity) in cerebral cortex neurones cultured for 9 days. The concentrations of the EAAs were chosen according to Frandsen and Schousboe [7] with exposure periods of $26 \mathrm{~h}$. Results are means of 9 experiments with S.E.M. $<3 \%$.

*Statistically significant differences between EAA and EAA + PB-treated cultures (Kruskal-Wallis test for non-parametric analyses; $P<0.001$ ). For further details concerning the LDH-leakage test see refs. 6 and 7.

\begin{tabular}{lcllll}
\hline & \multicolumn{5}{c}{ LDH activity in media (\% of total LDH) } \\
\cline { 2 - 6 } EAAs & $\begin{array}{l}\text { Conc. } \\
(\mu \mathrm{M})\end{array}$ & $\begin{array}{l}\text { Without } \\
\mathrm{PB}\end{array}$ & $\begin{array}{l}+\mathrm{PB} \\
(100 \mu \mathrm{M})\end{array}$ & $\begin{array}{l}+\mathrm{PB} \\
(500 \mu \mathrm{M})\end{array}$ & $\begin{array}{l}+\mathrm{GABA}^{\mathrm{a}} \\
(1 \mathrm{mM})\end{array}$ \\
\hline Control & 0 & 10 & 12 & 15 & 12 \\
Glutamate & 10 & 75 & 71 & 73 & 74 \\
Aspartate & 10 & 80 & 75 & 77 & 77 \\
NMDA & 300 & 80 & 83 & 82 & 81 \\
KA & 300 & 75 & $10^{*}$ & $12^{*}$ & 70 \\
QA & 300 & 70 & 67 & 71 & 70 \\
AMPA & 100 & 65 & 62 & 64 & 67 \\
\hline
\end{tabular}

aSimilar experimens $(n=6)$ with co-addition of GABA $(1 \mathrm{mM})$ and flunitrazepam $(10,50$ or $100 \mu \mathrm{M})$ gave comparable results.

Choi [12], and consistent with the notion that phenobarbital at these concentrations is not a GABA mimetic compound [15]. It has recently been reported [16] that GABA plus benzodiazepines reduce glutamate induced cell death in hippocampus, whereas GABA by itself has no such effect. The possibility therefore exists that co-exposure of the cells to GABA and flunitrazepam might protect against KA induced toxicity. However, addition of flunitrazepam $(10,50$ or $100 \mu \mathrm{M})$ together with $1 \mathrm{mM} \mathrm{GABA}$ immediately before exposure to KA had no effect on the KA-induced cell death (Table I). The lack of effect of addition of GABA also excludes the possibility that the effect of phenobarbital at the high concentrations might be due to an inhibition of GABA uptake [14] leading to increased extracellular concentrations of GABA.

The ability of $\mathrm{PB}$ to prevent the toxicity related to KA exposure was studied in more detail. It was found that exposure of the cultures to 100 or $500 \mu \mathrm{M} \mathrm{PB}$ per se did not affect the integrity of the cultures within the exposure period of $26 \mathrm{~h}$ which is in agreement with results obtained by Regan et al. [19] who used even longer exposure periods and higher concentrations of PB. Moreover, the dose-response relationship for the protection by $\mathrm{PB}$ of KA induced cytotoxicity was investigated. During a two hour exposure period to $300 \mu \mathrm{M} \mathrm{KA}, \mathrm{PB}$ was added at several different concentrations. Fig. 1 shows a classical dose-response relationship, and an $\mathrm{IC}_{50}$ value for the protective effect of PB of $56 \mu \mathrm{M}(5 \mu \mathrm{g} / \mathrm{ml})$ could be calculated by log-probit analysis. This $\mathrm{IC}_{50}$ value is well within the serum level of the barbiturate in patients treated with phenobarbital (cf. ref. 19). In case the ability of PB to protect against 


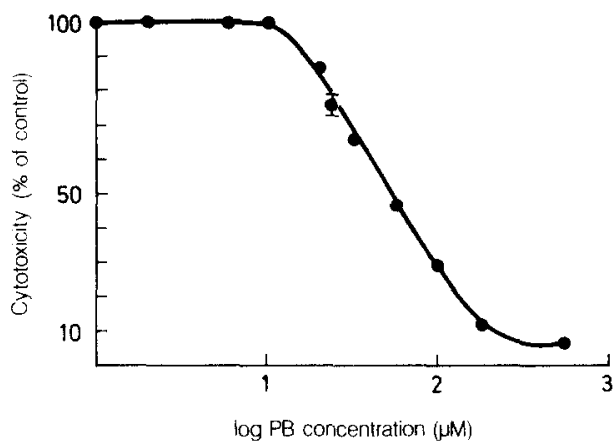

Fig. 1. Dose-response curve for the effect of $\mathrm{PB}$ on the cytotoxicity induced by $300 \mu \mathrm{M} \mathrm{KA}$ in cerebral cortex neurones cultured for 9 days. Toxicity was measured after $2 \mathrm{~h}$ of exposure to $300 \mu \mathrm{M} \mathrm{KA}$ and varying concentrations of $\mathrm{PB}$ using the lactate dehydrogenase $(\mathrm{LDH})$ leakage test described by Frandsen and Schousboe [6]. Results are means of 6 experiments. When exceeding the symbols, S.E.M. are indicated by vertical bars.

EAA induced neurotoxicity may have any therapeutic value it would be important to know whether the protective effect of PB depends upon the time of addition of $\mathrm{PB}$ relative to the exposure of the neurones to KA. Hence, it was investigated whether administration of $\mathrm{PB}$ shortly after the addition of KA would have any effect. However, no differences were observed between exposure of the cultures to KA alone or together with PB added 1-3 min after exposure to KA (results not shown). In the light of these results, a possible therapeutic use of low doses of PB does not seem promising, although prophylactic treatment is a possibility.

It is well known that exposure of nerve tissue to EAAs is initially associated with a substantial increase in respiratory activity [13]. To exclude a non-specific action of low concentrations of PB by a depression of the respiratory activity in the cultures, oxygen uptake was measured in the absence and presence of PB. Table II shows that

\section{TABLE II}

OXYGEN UPTAKE $\left(\mu \mathrm{mol} \times \mathrm{mg}^{-1} \times \mathrm{h}^{-1}\right)$ IN CEREBRAL CORTEX NEURONES CULTURED FOR 6-10 DAYS

$\mathrm{O}_{2}$ uptake was measured in cerebral cortex neurones using a Clarck-type $\mathrm{O}_{2}$ electrode as described in the text. The effects of $\mathrm{KA}$ or $\mathrm{PB}$ per se and $\mathrm{PB}+\mathrm{KA}$ were measured during a $4 \mathrm{~h}$ period. Results are means \pm S.E.M. with numbers of experiments given in parentheses.

Condition $\quad \mathrm{O}_{2}$-uptake $\left(\mu \mathrm{mol} \times \mathrm{mg}^{-1}\right.$ protein $\left.\times \mathrm{h}^{-1}\right)$

Basal

$50 \mu \mathrm{M} \mathrm{PB}$

$60 \mu \mathrm{M} \mathrm{KA}$, phase I

$60 \mu \mathrm{M} \mathrm{KA}$, phase II

$50 \mu \mathrm{MPB}+60 \mu \mathrm{M} \mathrm{KA}$

$\begin{array}{cc}4.43 \pm 0.15 & (12) \\ 4.20 \pm 0.25 & (3) \\ 6.79 \pm 0.45^{*} & (3) \\ 79.0 \pm 17.0^{* *} & (3) \\ 3.66 \pm 0.53 & (3)\end{array}$

Asteriks indicate statistically significant differences from the basal oxygen uptake (Student's $t$-test: ${ }^{*} P<$ 0.01 and ${ }^{* *} P<0.001$ ). 
the basal oxygen consumption of $4.43 \mu \mathrm{mol} \times \mathrm{mg}^{-1} \times \mathrm{h}^{-1}$, which is compatible with values obtained in similar and other nervous tissue preparations [11], was not affected by exposure to $\mathrm{PB}(50 \mu \mathrm{M})$. Likewise, $100 \mu \mathrm{M}$ PB was without effect on the basal $\mathrm{O}_{2}$ consumption (not shown). Exposure of the cultures to $60 \mu \mathrm{M} \mathrm{KA}$ which within the exposure period used does not induce any significant cytotoxicity [6] led to a moderate increase in the rate of oxygen consumption to $6.79 \mu \mathrm{mol} \times \mathrm{mg}^{-1} \times \mathrm{h}^{-1}$ during the first $50 \mathrm{~min}$ after addition of KA (phase I). It was consistently observed that this moderate increase in the respiratory rate was followed by a huge increase to 79 $\mu \mathrm{mol} \times \mathrm{mg}^{-1} \times \mathrm{h}^{-1}$ (phase II) which lasted for more than $1 \mathrm{~h}$ after which time it decreased, presumably due to lack of oxygen in the closed system. This ability of KA to increase the respiratory activity in the neurones is consistent with previous findings that respiration of nervous tissue preparations can be stimulated by exposure to either excitatory amino acids [13] or depolarizing concentrations of potassium [10]. It should be pointed out, however, that the increase in $\mathrm{O}_{2}$ consumption observed in the present study is much larger than previously published values for other nervous tissue preparations.

If the cultures were exposed to both $60 \mu \mathrm{M} \mathrm{KA}$ and $50 \mu \mathrm{M} \mathrm{PB}$ at the same time, the $\mathrm{KA}$-induced increase in $\mathrm{O}_{2}$ consumption (phase $\mathrm{I}$ and $\mathrm{II}$ ) was completely blunted. Since PB did not affect the basal $\mathrm{O}_{2}$ uptake in the cultures, the ability of PB to selectively abolish the $\mathrm{KA}$ induced increase in $\mathrm{O}_{2}$ uptake suggests that $\mathrm{PB}$ could exert its effects on both toxicity and oxygen consumption in a specific way, associated with a direct action on the KA receptor. Alternatively, PB might be interfering with intracellular events initiated via activation of KA but not other EAA receptors. Furthermore, the selectivity of $P B$ in protecting the cultures against cytotoxicity induced by KA but not by the other EAAs supports the notion that PB exerts its influence directly and selectively upon the KA receptors. Such specificity would explain the negative findings of Koh and Choi [12] and be in agreement with the differential potency of other barbiturates to reduce toxicity induced by various EAAs [18]. Further studies to establish whether $\mathrm{PB}$ can be considered a selective KA receptor subtype antagonist could be an important step in the development of potent and selective antagonists for the different EAA receptor subtypes. Studies aimed at establishing an effect of phenobarbital on $\left[{ }^{3} \mathrm{H}\right] \mathrm{KA}$ binding are currently being performed in this laboratory.

The expert technical assistance of Miss Charlotte Fredsee Andersen is gratefully acknowledged. The work was supported by grants from The Danish Biotechnology Program (1987-1990), the NOVO Foundation, the Lundbeck Foundation and Director J. Madsen's and wife O. Madsen's Foundation. Dr. W.E. Haefely, F. HoffmanLa Roche, Basel, Switzerland is cordially thanked for a generous gift of flunitrazepam.

1 Ben-Ari, Y., Limbic seizures and brain damage produced by kainic acid: mechanisms and relevance to human temporal epilepsia, Neuroscience, 14 (1985) 375-403.

2 Choi, D.W., Glutamate neurotoxicity in cortical cell culture is calcium dependent, Neurosci. Lett., 58 (1985) 293-297. 
3 Collins, G.G.S. and Anson, J., Effects of barbiturates on responses evoked by excitatory amino acids in slices of rat olfactory cortex, Neuropharmacology, 26 (1987) 167-171.

4 Dichter, M.A., Rat cortical-neurons in culture: methods, cell morphology, electrophysiology and synapse formation, Brain Res., 149 (1978) 279-293.

5 Drejer, J., Larsson, O.M. and Schousboe, A., Characterization of L-glutamate uptake into and release from astrocytes and neurons cultured from different brain regions, Exp. Brain Res., 47 (1982) 259 - 269.

6 Frandsen, Aa. and Schousboe, A., Time and concentration dependecy of the toxicity of excitatory amino acids on cerebral neurones in primary culture, Neurochem. Int., 10 (1987) 583-591.

7 Frandsen, Aa. and Schousboe, A., Development of excitatory amino acid induced cytotoxicity in cultured neurones, Int. J. Dev. Neurosci., in press.

8 Frandsen, Aa., Drejer, J. and Schousboe, A., Direct evidence thatexcitotoxicity in cultured neurons is mediated via $N$-methyl-D-aspartate (NMDA) as well as non-NMDA receptors, J. Neurochem., 53 (1989) 297-299.

9 Fuller, T.A. and Olney, J.W., Only certain anticonvulsants protect against kainate neurotoxicity, Neurobehav. Toxicol. Teratol., 3 (1981) 355-361.

10 Hertz, L. and Schousboe, A., Ion and energy metabolism of the brain at the cellular level, Int. Rev. Neurobiol., 18 (1975) 141-211.

11 Hertz, L., Drejer, J. and Schousboe, A., Energy metabolism in glutamatergic neurons, GABAergic neurons and astrocytes in primary cultures, Neurochem. Res., 13 (1988) 605-610.

12 Koh, J.-y. and Choi, D.W., Effect of anticonvulsant drugs on glutamate neurotoxicity in cortical cell culture, Neurology, 37 (1987) 319 322.

13 Krebs, H.A., Metabolism of amino-acids. III Deamination of amino-acids, Biochem. J., 29 (1935) $1620-1644$.

14 Larsson, O.M., Schousboe, A., Krogsgaard-larsen, P. and Hertz, L., Variations in the kinetic pattern of astrocytic $\gamma$-aminobutyric acid uptake when inhibited by different barbiturates, Biochem. Pharmacol., 31 (1982) 2694-2696.

15 Macdonald, R.L. and Barker, J.L., Different actions of anticonvulsant and anaestetic barbiturates revealed by use of cultured mammalian neurons, Science, 200 (1978), 775 777.

16 Mattson, M.P. and Kater, S.B., Excitatory and inhibitory neurotransmitters in the generation and degeneration of hippocampal neuroarchitecture, Brain Res., 478 (1989) 337-348.

17 Olney, J.W., Neurotoxicity of excitatory amino acids. In E.G. McGeer, J.W. Olney and P.L. McGeer (Eds.), Kainic Acid as a Tool in Neurobiology, New York, Raven, 1978, pp. 95-121.

18 Olney, J.W., Price, M.T., Fuller, T.A., Labruyerre, J., Samson, L., Carpenter, M. and Mahan, K., The anti-excitoxic effects of certain anaestetics, analgesics and sedative-hypnotics, Neurosci. Lett., 68 (1986) 29-34.

19 Regan, C.M., Gorman, A.M.C., Larsson, O.M., Macguire, C., Martin, M.L., Schousboe, A. and Williams, D.C., In vitro screening for anti-convulsant teratogenesis in neural primary cultures and cell lines, Int. J. Dev. Neurosci., in press.

20 Robinson, J. and Cooper, J.M., Method for determining oxygen consumptions in the biological media, suitable for calibration of the oxygen electrode, Anal. Biochem., 33 (1970) 390-399.

21 Willow, M. and Johnston, G.A.R., Pharmacology of barbiturates: Electrophysiological and neurochemical studies, Int. Rev. Neurobiol., 24 (1983) 15-49. 